\title{
Neutrotolerant acidophilic Streptomyces species isolated from acidic soils in China: Streptomyces guanduensis sp. nov., Streptomyces paucisporeus sp. nov., Streptomyces rubidus sp. nov. and Streptomyces yanglinensis sp. nov.
}

\author{
Correspondence \\ Ying Huang \\ huangy@im.ac.cn
}

\author{
Chunguang $\mathrm{Xu},{ }^{1,2}+$ Liming Wang, ${ }^{1}$ Oingfeng Cui, ${ }^{1}$ Ying Huang, ${ }^{1}$ \\ Zhiheng Liu, ${ }^{1}$ Guangyu Zheng ${ }^{2}$ and Michael Goodfellow ${ }^{3}$ \\ ${ }^{1}$ State Key Laboratory of Microbial Resources, Institute of Microbiology, Chinese Academy of \\ Sciences, Beijing 100080, People's Republic of China \\ ${ }^{2}$ College of Life Sciences, Beijing Normal University, Beijing 100875, People's Republic of \\ China \\ ${ }^{3}$ School of Biology, University of Newcastle, Newcastle upon Tyne NE1 7RU, UK
}

Streptomycete systematics has been directed towards unravelling relationships between neutrophilic strains that, in culture, grow between $\mathrm{pH} 5.0$ and 9.0 with an optimum around neutrality (Williams et al., 1983; Manfio et al., 1995; Liu et al., 2005). In contrast, acidophilic actinomycetes, which share key chemotaxonomic and morphological properties with neutrophilic streptomycetes, have received little attention, though they are known to be common in terrestrial habitats with low $\mathrm{pH}$ values (Williams et al., 1971; Khan \& Williams, 1975; Goodfellow \& Dawson, 1978; Seong et al., 1993). It is of interest to clarify the taxonomy of these

†Present address: Hu Lunbeir College, City of Hu Lunbeir 021008 People's Republic of China.

The GenBank/EMBL/DDBJ accession numbers for the 16S rRNA gene sequences of strains $317,701^{\top}, 913,1307^{\top}, 13 c 15^{\top}$ and $1413^{\top}$ are AY882019, AY876942, AY882020, AY876940, AY876941 and AY876943, respectively. organisms, not least because they are involved in the decomposition of fungal biomass in acid litters and soils (Williams \& Robinson, 1981) and produce antifungal antibiotics (Williams \& Khan, 1974) and acid-stable enzymes (Williams \& Flowers, 1978; Williams \& Robinson, 1981).

Acidophilic sporoactinomycetes can be assigned to two groups: neutrotolerant acidophilic strains grow from $\mathrm{pH} 4 \cdot 5$ to $7 \cdot 5$, with an optimum between $\mathrm{pH} 5 \cdot 0$ and $5 \cdot 5$; strictly acidophilic strains grow from $\mathrm{pH} 3 \cdot 5$ to $6 \cdot 5$, with an optimum around $4 \cdot 5$ (Williams et al., 1971; Lonsdale, 1985). Members of the latter group have been assigned to the genus Streptacidiphilus, which currently contains four species (Kim et al., 2003; Huang et al., 2004). Neutrotolerant acidophilic actinomycetes form a taxonomically diverse group within the range of variation encompassed by the genus Streptomyces (Williams et al., 1971; Lonsdale, 1985; Seong, 1992), but only one species has a validly published name, Streptomyces yeochonensis (Kim et al., 2004). In the present study, 
six neutrotolerant acidophilic actinomycetes isolated from acidic soils were the subjects of a polyphasic study designed to clarify their taxonomic status. It was evident from the resultant data that the organisms represented four novel, but closely related, Streptomyces species.

The six strains were isolated on an acidified isolation medium (Huang et al., 2004) supplemented with cycloheximide and nystatin (each at $50 \mu \mathrm{g} \mathrm{ml}^{-1}$ ). The isolation plates were inoculated with soil suspensions prepared using a dispersion and differential centrifugation procedure (Wang et al., 2003). The soil samples ( $\mathrm{pH} 5 \cdot 1-6 \cdot 5)$ were collected from pineforest soils in Yunnan Province, China; isolates 317 and 913 were from Diaocenshan Mountain, isolates $701^{\mathrm{T}}$ and $1413^{\mathrm{T}}$ were from Guandu and isolates $1307^{\mathrm{T}}$ and $13 \mathrm{c} 15^{\mathrm{T}}$ were from Yanglin. The strains were maintained as suspensions of mycelial fragments and spores in glycerol $(20 \%, \mathrm{v} / \mathrm{v})$ at $-20{ }^{\circ} \mathrm{C}$ and on either yeast extract/malt extract agar (ISP medium 2; Shirling \& Gottlieb, 1966) or oatmeal agar (ISP medium 3; Shirling \& Gottlieb, 1966) that had been adjusted to an initial $\mathrm{pH}$ of $5 \cdot 5$ using a citric acid $(0 \cdot 1 \mathrm{M}) /$ $\mathrm{Na}_{2} \mathrm{HPO}_{4}(0 \cdot 2 \mathrm{M})$ buffer. Biomass for chemotaxonomic and molecular systematic studies was grown in shake flasks of acidified ISP medium 2 broth at $28^{\circ} \mathrm{C}$ for between 3 and 6 days and then harvested by centrifugation. Cells for chemotaxonomic studies were washed twice in distilled water and Tris-EDTA buffer ( $10 \mathrm{mM}$ Tris, $1 \mathrm{mM}$ EDTA; $\mathrm{pH} 8 \cdot 0$ ) and stored at $-20^{\circ} \mathrm{C}$ until required.

Extraction of chromosomal DNA, PCR amplification and sequencing of $16 \mathrm{~S}$ rRNA genes from the test strains were carried out using established procedures (Kim et al., 1998). The resultant sequence data were aligned with those of members of representative Streptomyces species by using the CLUSTAL X 1.8 program (Thompson et al., 1997) and the alignments were checked manually. Phylogenetic trees were generated by using the least-squares (Fitch \& Margoliash, 1967), maximum-likelihood (Felsenstein, 1981), maximum-parsimony (Kluge \& Farris, 1969) and neighbourjoining (Saitou \& Nei, 1987) tree-making algorithms from the PHYLIP 3.5c package (Felsenstein, 1993) and the TREECON program, version 1.3b (Van de Peer \& De Wachter, 1994). Phylogenetic distances were calculated as described by Kimura (1980). The topology of the phylogenetic trees was tested by bootstrap analysis (Felsenstein, 1985) of the neighbour-joining data using the SEQBOOT and CONSENSE programs from the PHYLIP suite (Felsenstein, 1993).

Almost complete 16S rRNA gene sequences (1411-1447 nt) were obtained for the six isolates. Preliminary phylogenetic analysis, which included almost complete full-length sequences of type strains of the family Streptomycetaceae, showed that the isolates fell within the evolutionary radiation encompassed by the genus Streptomyces (data not shown). The organisms shared 16S rRNA gene sequence similarities of more than $96.5 \%$ with many Streptomyces species with validly published names, while the corresponding values for streptacidiphili ranged from $94 \cdot 4$ to $95 \cdot 6 \%$, results which indicate that the isolates are bona fide streptomycetes. In an analysis restricted to Streptomyces strains, the isolates formed a distinct phyletic line in the Streptomyces tree together with the type strain of Streptomyces yeochonensis, an organism previously shown to form a distinct lineage in the Streptomyces phylogenetic tree (Kim et al., 2004).

Chemotaxonomic and morphological studies were carried out on the six isolates to establish whether they had properties consistent with their assignment to the genus Streptomyces. The strains were grown on acidified oatmeal agar plates at $28{ }^{\circ} \mathrm{C}$ for 14 days and then examined by eye to determine aerial spore-mass colour, substrate mycelial pigmentation and the colours of any diffusible pigments. The micromorphology of the mycelium was observed by light microscopy using the coverslip technique of Kawato \& Shinobu (1959). Spore-chain morphology and sporesurface ornamentation were established by examining gold-coated dehydrated specimens using a FEI QUANTA electron microscope. Standard procedures were used for the extraction and analysis of fatty acids (MIDI system; http:// www.midi-inc.com), diagnostic isomers of diaminopimelic acids (Lechevalier \& Lechevalier, 1980; Hasegawa et al., 1983), isoprenoid quinones (Collins, 1985; Wu et al., 1989), polar lipids (Minnikin et al., 1984) and sugars (Lechevalier \& Lechevalier, 1980). The G $+C$ content of the genomic DNA was determined by using the thermal denaturation method (Marmur \& Doty, 1962) with Escherichia coli CGMCC 1.365 as the control.

The morphological and chemical features of the isolates were consistent with assignment to the genus Streptomyces (Williams et al., 1989; Manfio et al., 1995). The organisms formed an extensively branched substrate mycelium and aerial hyphae that carried smooth-surfaced spores in flexuous spore chains. They contained major amounts of LL-diaminopimelic acid and minor proportions of the corresponding meso- component in whole-organism hydrolysates, hexahydrogenated and octahydrogenated menaquinones with nine isoprene units [MK-9 $\left.\left(\mathrm{H}_{6}\right), \mathrm{MK}-9\left(\mathrm{H}_{8}\right)\right]$ as the predominant isoprenologues and diphosphatidylglycerol, phosphatidylethanolamine, phosphatidylmethylethanolamine and phosphatidylinositol mannosides as the major polar lipids (phospholipid type II sensu Lechevalier et al., 1977); they lacked mycolic acids and characteristic sugars. The fatty acid profiles consisted mainly of saturated straight-chain and iso- and anteiso-branched-chain components (fatty acid type 2c sensu Kroppenstedt, 1985). The DNA $\mathrm{G}+\mathrm{C}$ composition of the isolates was within the range 70-75 $\mathrm{mol} \%$.

The tested strains and the type strain of $S$. yeochonensis formed several lineages in the S. yeochonensis $16 \mathrm{~S}$ rRNA gene sequence subclade (Fig. 1). Isolates 317, 913 and $1307^{\mathrm{T}}$ share sequence similarities within the range 99.7-100\%, values that correspond to 2 and 0 nt differences at 1404 and 1411 locations, respectively. It is also interesting that this taxon was highlighted by all of the tree-making algorithms and was supported by a $100 \%$ bootstrap value in the neighbour-joining analysis. Strain $1413^{\mathrm{T}}$ is loosely 


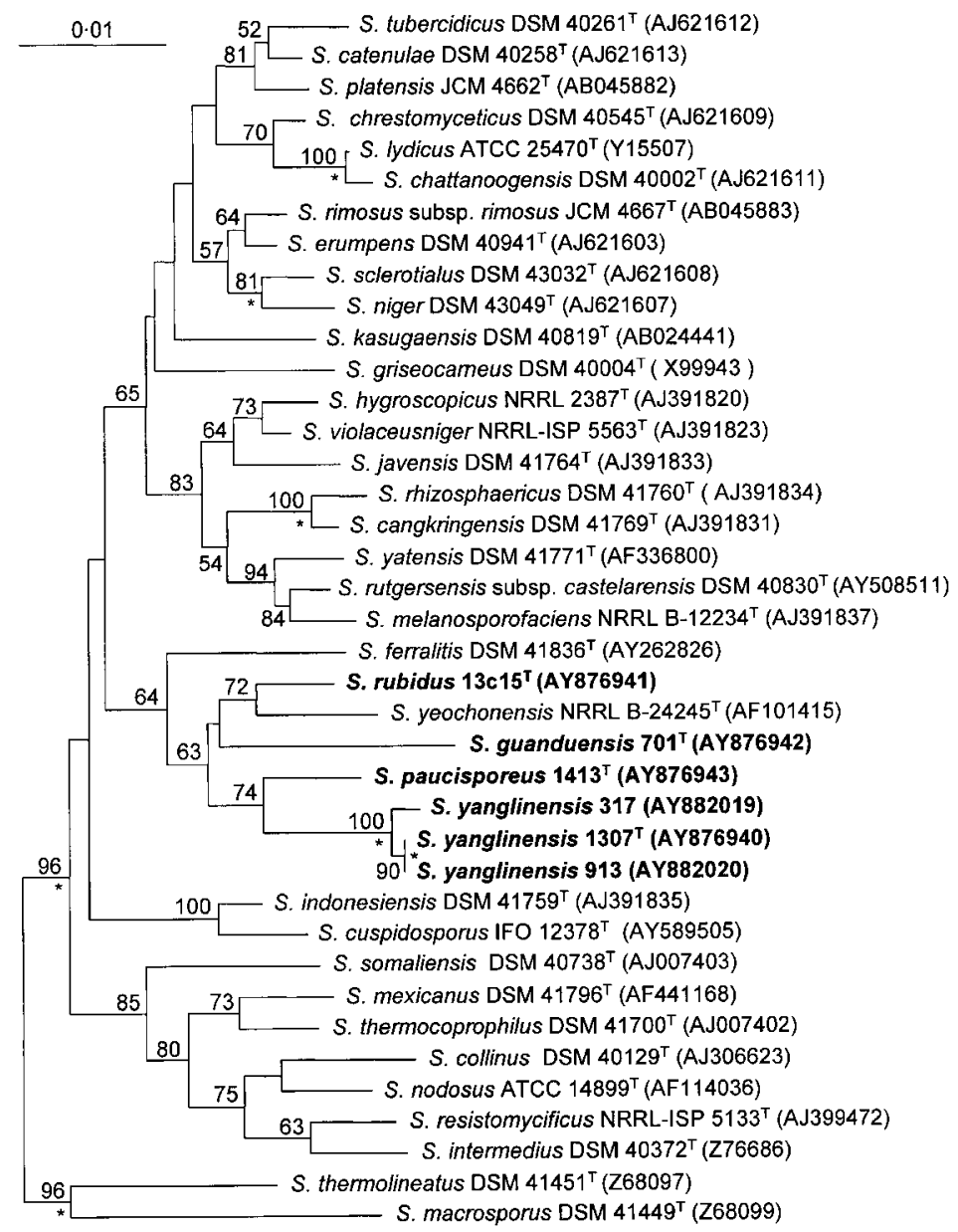

Fig. 1. Neighbour-joining tree (Saitou \& Nei, 1987), based on almost complete $16 \mathrm{~S}$ rRNA gene sequences, showing the phylogenetic relationships between the isolates and related species of the genus Streptomyces. Asterisks indicate branches that were recovered using the least-squares (Fitch \& Margoliash, 1967), maximum-likelihood (Felsenstein, 1981) and maximum-parsimony (Kluge \& Farris, 1969) tree-making algorithms. Numbers at nodes indicate levels of bootstrap support (\%) based on 1000 resampled datasets; only values above $50 \%$ are given. Bar, 0.01 substitutions per nucleotide position.

associated with this group, sharing its closest similarity with isolate $1307^{\mathrm{T}}$; the two strains shared a $16 \mathrm{~S}$ rRNA gene sequence similarity of $98.6 \%$, a value equivalent to $20 \mathrm{nt}$ differences at 1414 locations. Similarly, strain $13 \mathrm{c} 15^{\mathrm{T}}$ was loosely associated with the type strain of $S$. yeochonensis (Table 1). The final isolate, strain $701^{\mathrm{T}}$, was most closely related to isolate $13 \mathrm{c}^{2} 5^{\mathrm{T}}$; the two organisms shared a sequence similarity of $97 \cdot 8 \%$, a value that corresponds to $31 \mathrm{nt}$ differences at 1396 sites.
The fluorescent microplate method of Ezaki et al. (1989) was used to determine DNA-DNA relatedness values between the following strains: isolates $701^{\mathrm{T}}, 1307^{\mathrm{T}}, 13 \mathrm{c} 15^{\mathrm{T}}, 1413^{\mathrm{T}}$ and S. yeochonensis NRRL B-24245 ${ }^{\mathrm{T}}$. Photobiotin-labelled DNA from each of the strains was individually hybridized with single-stranded unlabelled DNA samples of the remaining strains, non-covalently bound to microtitre wells. The hybridization experiments were carried out under stringent conditions in $50 \%$ formamide at $50{ }^{\circ} \mathrm{C}$, and the DNA

Table 1. 16S rRNA gene sequence similarities and DNA-DNA relatedness values between the species in the $S$. yeochonensis 16S rRNA gene sequence subclade

Values above the diagonal are DNA-DNA relatedness values (\%), whereas values below the diagonal are $16 \mathrm{~S}$ rRNA gene sequence similarities (\%).

\begin{tabular}{|lccccc|}
\hline Strain & $\mathbf{7 0 1}^{\mathbf{T}}$ & $\mathbf{1 3 0 7}^{\mathbf{T}}$ & $\mathbf{1 3 \mathbf { c 1 5 }}^{\mathbf{T}}$ & $\mathbf{1 4 1 3}^{\mathbf{T}}$ & ${\mathbf{N R R L ~} \mathbf{B}-\mathbf{2 4 2 4 5}^{\mathbf{T}}}^{\mathbf{N}^{\mathrm{T}}}$ \\
$701^{\mathrm{T}}$ & & $23 \cdot 1$ & $21 \cdot 4$ & $14 \cdot 9$ & $18 \cdot 7$ \\
$1307^{\mathrm{T}}$ & $97 \cdot 5$ & & $23 \cdot 8$ & $25 \cdot 9$ & $21 \cdot 0$ \\
$13 \mathrm{c} 15^{\mathrm{T}}$ & $97 \cdot 8$ & $97 \cdot 9$ & & $19 \cdot 9$ & $43 \cdot 0$ \\
$1413^{\mathrm{T}}$ & $97 \cdot 1$ & $98 \cdot 6$ & $97 \cdot 9$ & & $35 \cdot 0$ \\
S. yeochonensis NRRL B-24245 & $97 \cdot 4$ & $98 \cdot 0$ & $98 \cdot 7$ & $98 \cdot 2$ & \\
\hline
\end{tabular}


hybridization rates were detected according to Christensen et al. (2000) by using a FLUOstar OPTIMA microplate reader (BMG LABTECH). Mean percentage DNA-DNA relatedness values were calculated from quadruplicate hybridization experiments and expressed as means of the corresponding reciprocal values. It was evident from the resultant data that all of the strains tested belong to different genomic species, as they shared DNA-DNA relatedness values between 14.9 and $43.0 \%$ (Table 1) - well below the $70 \%$ cut-off point recommended for the assignment of strains to the same genomic species (Wayne et al., 1987). The same method was used to determine the corresponding relatedness values between isolates 317,913 and $1307^{\mathrm{T}}$ : they shared relatedness values of more than $89 \%$.

S. yeochonensis NRRL B- $24245^{\mathrm{T}}$ and all of the isolates were examined for a range of phenotypic properties, using established procedures (Williams et al., 1983; Seong et al., 1993), albeit with media adjusted to $\mathrm{pH} 5 \cdot 5$. The organisms were also examined for their ability to produce melanin pigments on acidified peptone/yeast extract/iron agar (ISP medium 6; Shirling \& Gottlieb, 1966) and tyrosine agar (ISP medium 7; Shirling \& Gottlieb, 1966) plates after 14 days at $28^{\circ} \mathrm{C}$. It is evident from Table 2 that the strains gave phenotypic profiles that matched the lineages detected in the $S$. yeochonensis $16 \mathrm{~S}$ rRNA gene sequence subclade. In particular, it is apparent that isolates 317,913 and $1307^{\mathrm{T}}$ have identical phenotypic profiles. All of the isolates showed a greater capacity than the $S$. yeochonensis strain to utilize carbon sources for energy and growth.

It is evident from the genotypic and phenotypic data that the six neutrotolerant acidophilic isolates can be assigned to four novel species in the genus Streptomyces. Consequently,

Table 2. Phenotypic properties that separate organisms assigned to distinct lineages in the $S$. yeochonensis $16 \mathrm{~S}$ rRNA gene sequence subclade

Strains: 1 , isolate $701^{\mathrm{T}} ; 2$, isolates 317,913 and $1307^{\mathrm{T}} ; 3$, isolate $13 \mathrm{c}^{\mathrm{T}} 5^{\mathrm{T}} ; 4$, isolate $1413^{\mathrm{T}} ; 5$, S. yeochonensis NRRL B- $24245^{\mathrm{T}}$. + , Positive; ${ }^{\mathrm{W}}{ }^{\mathrm{W}}$, weakly positive; - , negative.

\begin{tabular}{|c|c|c|c|c|c|}
\hline Characteristic & 1 & 2 & 3 & 4 & 5 \\
\hline \multicolumn{6}{|l|}{ Appearance on oatmeal agar } \\
\hline Aerial hyphae & Sparse & Abundant & Abundant & Sparse & Abundant \\
\hline Aerial spore-mass colour & White to grey & Grey & Mahogany & Grey & Grey \\
\hline Melanin production on tyrosine agar & - & - & - & + & - \\
\hline \multicolumn{6}{|l|}{ Degradation of $(\%, w / v)$ : } \\
\hline Aesculin $(0 \cdot 1)$ & - & + & + & + & + \\
\hline Casein $(1 \cdot 0)$ & - & - & - & + & + \\
\hline Hypoxanthine $(0 \cdot 4)$ & - & + & - & - & - \\
\hline L-Tyrosine $(0 \cdot 4)$ & - & - & - & - & - \\
\hline Xylan $(0 \cdot 4)$ & - & + & + & - & - \\
\hline \multicolumn{6}{|l|}{$\begin{array}{l}\text { Growth on sole carbon sources } \\
\text { (at } 1 \%, \mathrm{w} / \mathrm{v})\end{array}$} \\
\hline L-Arabinose & + & + & + & $+{ }^{\mathrm{W}}$ & - \\
\hline D-Fructose & + & + & + & - & - \\
\hline Glycerol & - & + & + & - & - \\
\hline D-Mannose & + & + & $+{ }^{\mathrm{W}}$ & - & - \\
\hline myo-Inositol & $+{ }^{\mathrm{W}}$ & - & - & - & - \\
\hline D-Raffinose & + & + & + & - & - \\
\hline L-Rhamnose & + & + & - & + & - \\
\hline L-Sorbose & + & + & $+{ }^{\mathrm{w}}$ & + & - \\
\hline D-Sucrose & + & + & + & - & - \\
\hline D-Trehalose & + & + & - & + & - \\
\hline D-Xylose & + & + & + & - & - \\
\hline \multicolumn{6}{|l|}{$\begin{array}{l}\text { Growth on sole carbon sources } \\
\text { (at } 0 \cdot 1 \%, \mathrm{w} / \mathrm{v})\end{array}$} \\
\hline L-Alanine & - & - & - & $+{ }^{\mathrm{W}}$ & - \\
\hline L-Arginine & - & - & $+{ }^{\mathrm{w}}$ & + & - \\
\hline L-Phenylalanine & + & - & - & + & - \\
\hline \multicolumn{6}{|l|}{ Growth at: } \\
\hline $\mathrm{pH} 4 \cdot 5$ & + & + & $+{ }^{\mathrm{W}}$ & $+{ }^{\mathrm{W}}$ & + \\
\hline $\mathrm{pH} 7 \cdot 5$ & - & - & - & $+{ }^{\mathrm{W}}$ & + \\
\hline
\end{tabular}


we propose the names Streptomyces guanduensis sp. nov. for isolate $701^{\mathrm{T}}$, Streptomyces paucisporeus sp. nov. for isolate $1413^{\mathrm{T}}$, Streptomyces rubidus sp. nov. for isolate $13 \mathrm{c} 15^{\mathrm{T}}$ and Streptomyces yanglinensis sp. nov. for isolates 317,913 and $1307^{\mathrm{T}}$.

\section{Description of Streptomyces guanduensis sp. nov.}

Streptomyces guanduensis (gu.an.du.en'sis. N.L. masc. adj. guanduensis belonging to Guandu, the source of the soil from which the type strain was isolated).

Aerobic, Gram-positive, non-motile, neutrotolerant, acidophilic streptomycete that forms branched substrate and aerial hyphae. Smooth-surfaced spores are borne in flexuous spore chains. Deep-brown colonies that carry a white to grey aerial spore mass are formed on oatmeal agar, ISP medium 9 supplemented with glucose $(1 \%, \mathrm{w} / \mathrm{v})$ and on yeast extract/ malt extract agar. Diffusible pigments are not formed and melanin pigments are not produced on peptone/yeast extract/iron agar or tyrosine agar. Growth occurs at temperatures between 20 and $37^{\circ} \mathrm{C}$, but not at $15^{\circ} \mathrm{C}$, and at $\mathrm{pH}$ values from $4 \cdot 5$ to $7 \cdot 0$, but not at $\mathrm{pH} 3 \cdot 5$. Degrades Tween 80 , but not adenine, guanine, starch or xanthine. D-Cellobiose, D-galactose, D-glucose, D-inulin, D-lactose, D-mannitol, D-salicin (each at $1 \%, \mathrm{w} / \mathrm{v}$ ), adipic acid and L-phenylalanine (each at $0 \cdot 1 \%, \mathrm{w} / \mathrm{v}$ ) are used as sole carbon sources for energy and growth, but adonitol, D-sorbitol (each at $1 \%$, w/v), L-alanine, DL-aminobutyric acid, L-arginine, $\alpha$-L-aspartic acid, L-cysteine, L-valine, sodium acetate, sodium citrate and sodium oxalate (each at $0 \cdot 1 \%$, $\mathrm{w} / \mathrm{v}$ ) are not. Does not use L-alanine, L-arginine, $\alpha$-L-aspartic acid, L-glutamic acid, L-isoleucine or L-phenylalanine (each at $0 \cdot 1 \%, w / v)$ as sole carbon and nitrogen sources. Does not grow in the presence of $5 \%(\mathrm{w} / \mathrm{v}) \mathrm{NaCl}$. The organism is sensitive to filter-paper discs soaked in the following ( $\mu \mathrm{g} \mathrm{ml}^{-1}$ unless indicated): acetylspiramycin (15), carbenicillin (10), cephalothin (30), ciprofloxacin (5), doxycycline hydrochloride (30), erythromycin (15), josamycin (15), kanamycin sulphate (30), minocycline hydrochloride (30), neomycin sulphate (30), ofloxacin (5), rifampicin (5), streptomycin sulphate (10), tetracycline hydrochloride (30) and tobramycin sulphate (10), but not to amoxicillin (10), ampicillin (10), azithromycin (30), aztreonam (30), penicillin $\mathrm{G}\left(10 \mathrm{IU} \mathrm{ml}^{-1}\right)$ or sulfamethoxazole (25). Additional properties are shown in Table 2 . The DNA G+C content is $72.7 \mathrm{~mol} \%$. Chemotaxonomic properties are typical of members of the genus Streptomyces.

The type (and only) strain, $701^{\mathrm{T}}$ ( = CGMCC $4.2022^{\mathrm{T}}=\mathrm{JCM}$ $13274^{\mathrm{T}}$ ), was isolated from Dashao pine-forest soil in Guandu, Yunnan Province, People's Republic of China.

\section{Description of Streptomyces paucisporeus sp. nov.}

Streptomyces paucisporeus (pau.ci.spo're.us. L. adj. paucus few; N.L. adj. sporeus spored; N.L. masc. adj. paucisporeus few spored, forming few spores).
Aerobic, Gram-positive, non-motile, neutrotolerant, acidophilic streptomycete that forms branched substrate and aerial hyphae. Khaki-coloured colonies that carry a white to grey aerial spore mass are formed on acidified oatmeal agar, yeast extract/starch agar and yeast extract/malt extract agar. A few spores with smooth surfaces are borne in short flexuous spore chains. Diffusible pigments are not formed, though melanin pigments are produced on tyrosine agar but not on peptone/yeast extract/iron agar. Growth occurs at temperatures between 20 and $37^{\circ} \mathrm{C}$, but not at $15^{\circ} \mathrm{C}$, and at $\mathrm{pH}$ values from $4 \cdot 5$ to $7 \cdot 5$, but not at $\mathrm{pH} 3 \cdot 5$. Degrades Tween 80 , but not adenine, guanine, starch or xanthine. DCellobiose, D-galactose, D-glucose, D-mannitol, D-sorbitol (each at $1 \%, \mathrm{w} / \mathrm{v}), \mathrm{L}$-alanine, $\mathrm{L}$-arginine, $\alpha$-L-aspartic acid, L-cysteine, L-glutamic acid, L-phenylalanine and L-valine (each at $0 \cdot 1 \%, w / v)$ are used as sole carbon sources for energy and growth, but adonitol, inulin, D-lactose (each at $1 \%$, w/v), adipic acid, DL-aminobutyric acid, sodium acetate, sodium citrate and sodium oxalate (each at $0.1 \%$, $\mathrm{w} / \mathrm{v}$ ) are not. Does not use L-alanine, L-arginine, L-aspartic acid, L-glutamic acid, L-isoleucine or L-phenylalanine (each at $0 \cdot 1 \%, \mathrm{w} / \mathrm{v}$ ) as sole carbon and nitrogen sources. Does not grow in the presence of $5 \%(\mathrm{w} / \mathrm{v}) \mathrm{NaCl}$. The organism is sensitive to filter-paper discs soaked in the following ( $\mu \mathrm{g} \mathrm{ml}^{-1}$ unless indicated): azithromycin (30), doxycycline hydrochloride (30), erythromycin (15), josamycin (15), kanamycin sulphate (30), minocycline hydrochloride (30), neomycin sulphate (30), streptomycin sulphate (10), tetracycline hydrochloride (30) and tobramycin sulphate (10), but not to filter-paper discs soaked in acetylspiramycin (15), amoxicillin (10), ampicillin (10), aztreonam (30), carbenicillin (10), cephalothin (30), ciprofloxacin (5), ofloxacin (5), penicillin $\mathrm{G}\left(10 \mathrm{IU} \mathrm{ml}^{-1}\right)$, rifampicin (5) or sulfamethoxazole (25). Additional properties are shown in Table 2. The DNA G + C content is $74 \cdot 8 \mathrm{~mol} \%$. Chemotaxonomic properties are typical of the genus Streptomyces.

The type (and only) strain, $1413^{\mathrm{T}}$ (=CGMCC $4.2025^{\mathrm{T}}=$ JCM $13276^{\mathrm{T}}$ ), was isolated from Dashao pine-forest soil in Guandu, Yunnan Province, People's Republic of China.

\section{Description of Streptomyces rubidus sp. nov.}

Streptomyces rubidus (ru'bi.dus. L. masc. adj. rubidus dark red).

Aerobic, Gram-positive, non-motile, neutrotolerant, acidophilic streptomycete that forms branched substrate and aerial hyphae. Smooth-surfaced spores are borne in flexuous spore chains. Mahogany-coloured substrate mycelium, sparse aerial hyphae and diffusible pigments are formed on oatmeal agar and yeast extract/malt extract agar. Melanin pigments are not produced on tyrosine agar or peptone/ yeast extract/iron agar. Growth occurs at temperatures between 20 and $37^{\circ} \mathrm{C}$, but not at $15^{\circ} \mathrm{C}$, and at $\mathrm{pH}$ values from $4 \cdot 5$ to $7 \cdot 0$, but not at $\mathrm{pH} 3 \cdot 5$. Starch and Tween 80 are degraded, but adenine, guanine and xanthine are not. D-Cellobiose, D-galactose, D-glucose, D-lactose, D-mannitol, D-salicin (each at $1 \%, \mathrm{w} / \mathrm{v}), \mathrm{L}$-arginine and sodium citrate 
$(0 \cdot 1 \%, \mathrm{w} / \mathrm{v})$ are used as sole carbon sources for energy and growth, but adonitol, inulin, D-sorbitol (each at $1 \%, \mathrm{w} / \mathrm{v}$ ), adipic acid, L-alanine, DL-aminobutyric acid, $\alpha$-L-aspartic acid, L-cysteine, L-phenylalanine, sodium acetate, sodium oxalate and L-valine (each at $0 \cdot 1 \%, \mathrm{w} / \mathrm{v}$ ) are not. L-Alanine is used as a sole carbon and nitrogen source, but L-arginine, $\alpha$-L-aspartic acid, L-glutamic acid, L-isoleucine and Lphenylalanine (each at $0 \cdot 1 \%, \mathrm{w} / \mathrm{v}$ ) are not. Does not grow in the presence of $5 \%(\mathrm{w} / \mathrm{v}) \mathrm{NaCl}$. Sensitive to filterpaper discs soaked in the following $\left(\mu \mathrm{g} \mathrm{ml}{ }^{-1}\right.$ unless indicated): azithromycin (30), aztreonam (30), carbenicillin (10), cephalothin (30), ciprofloxacin (5), doxycycline hydrochloride (30), erythromycin (15), josamycin (15), kanamycin sulphate (30), minocycline hydrochloride (30), neomycin sulphate (30), streptomycin sulphate (10), tetracycline hydrochloride (30) and tobramycin sulphate (10), but resistant to filter-paper discs soaked in acetylspiramycin (15), amoxicillin (10), ampicillin (10), ofloxacin (5), penicillin $\mathrm{G}$ (10 $\mathrm{IU} \mathrm{ml}^{-1}$ ), rifampicin (5) and sulfamethoxazole (25). Additional phenotypic properties are shown in Table 2. The DNA G $+\mathrm{C}$ content is $70.6 \mathrm{~mol} \%$. Chemotaxonomic properties are typical of members of the genus Streptomyces.

The type (and only) strain, $13 \mathrm{c} 15^{\mathrm{T}}$ (CGMCC $4.2026^{\mathrm{T}}=\mathrm{JCM}$ $13277^{\mathrm{T}}$ ), was isolated from a pine-forest soil in Yanglin, Yunnan Province, People's Republic of China.

\section{Description of Streptomyces yanglinensis sp. nov.}

Streptomyces yanglinensis (yang.lin.en'sis. N.L. masc. adj. yanglinensis belonging to Yanglin, the source of the soil from which the type strain was isolated).

Aerobic, Gram-positive, non-motile, neutrotolerant, acidophilic streptomycete that forms branched substrate and aerial hyphae. Grey-coloured colonies that carry an abundant white to grey aerial spore mass are formed on acidified oatmeal agar; blackish colonies bearing an abundant white to grey aerial spore mass are formed on ISP 9 agar supplemented with fructose, mannose or sucrose (each at $1 \%$, w/v). Smooth-surfaced spores are borne on flexuous spore chains. Diffusible pigments are not produced, and melanin pigments are not formed on peptone/yeast extract/iron agar or tyrosine agar. Growth occurs at temperatures between 20 and $37^{\circ} \mathrm{C}$, but not at $15^{\circ} \mathrm{C}$, and at $\mathrm{pH}$ values between $4 \cdot 5$ and $7 \cdot 0$, but not at $\mathrm{pH} 3 \cdot 5$. Degrades starch and Tween 80 , but not adenine, guanine or xanthine. Adonitol, D-cellobiose, D-galactose, D-glucose, D-inulin, D-lactose, D-mannitol, D-salicin and D-sorbitol (each at $1 \%$, w/v) are used as sole carbon sources for energy and growth, but D-melezitose (at $1 \%, \mathrm{w} / \mathrm{v}$ ), adipic acid, L-alanine, DLaminobutyric acid, L-arginine, $\alpha$-L-aspartic acid, L-cysteine, L-phenylalanine, L-valine, sodium acetate, sodium citrate and sodium oxalate (each at $0 \cdot 1 \%, \mathrm{w} / \mathrm{v}$ ) are not. L-Glutamic acid is used as a sole carbon and nitrogen source, but L-alanine, L-arginine, L-aspartic acid, L-isoleucine and L-phenylalanine (each at $0 \cdot 1 \%, \mathrm{w} / \mathrm{v})$ are not. Does not grow in the presence of $5 \%(\mathrm{w} / \mathrm{v}) \mathrm{NaCl}$. Sensitive to filterpaper discs soaked in the following $\left(\mu \mathrm{g} \mathrm{ml}^{-1}\right.$ unless indicated): cephalothin (30), doxycycline hydrochloride (30), erythromycin (15), josamycin (15), kanamycin sulphate (30), minocycline hydrochloride (30), neomycin sulphate (30), sulfamethoxazole (25) and tobramycin sulphate (10), but not to filter-paper discs soaked in acetylspiramycin (15), amoxicillin (10), ampicillin (10), azithromycin (30), aztreonam (30), carbenicillin (10), ciprofloxacin (5), ofloxacin (5), penicillin $\mathrm{G}$ (10 IU ml $\mathrm{IJ}^{-1}$ ), rifampicin (5), streptomycin sulphate (10) or tetracycline hydrochloride (30). Additional phenotypic properties are shown in Table 2. The DNA $\mathrm{G}+\mathrm{C}$ content is $74 \cdot 8 \mathrm{~mol} \%$. Chemotaxonomic properties are typical of the genus Streptomyces.

The type strain, $1307^{\mathrm{T}}\left(=\mathrm{CGMCC} 4.2023^{\mathrm{T}}=\mathrm{JCM} 13275^{\mathrm{T}}\right)$, was isolated from a pine-forest soil in Yanglin, Yunnan Province, People's Republic of China.

\section{Acknowledgements}

This work was supported through the Royal Society-Chinese Academy of Sciences Exchange Scheme (grant number Q 814) and by grants from the National Nature Science Foundation of China (nos 30270003 and 30370002). The authors are grateful to Dr J. P. Euzéby (Toulouse) for his invaluable help with the nomenclature.

\section{References}

Christensen, H., Angen, O., Mutters, R., Olsen, J. E. \& Bisgaard, M. (2000). DNA-DNA hybridization determined in micro-wells using covalent attachment of DNA. Int J Syst Evol Microbiol 50, 1095-1102.

Collins, M. D. (1985). Isoprenoid quinone analysis in classification and identification. In Chemical Methods in Bacterial Systematics, pp. 267-287. Edited by M. Goodfellow \& D. E. Minnikin. London: Academic Press.

Ezaki, T., Hashimoto, Y. \& Yabuuchi, E. (1989). Fluorometric deoxyribonucleic acid-deoxyribonucleic acid hybridization in microdilution wells as an alternative to membrane filter hybridization in which radioisotopes are used to determine genetic relatedness among bacterial strains. Int J Syst Bacteriol 39, 224-229.

Felsenstein, J. (1981). Evolutionary trees from DNA sequences: a maximum likelihood approach. J Mol Evol 17, 368-376.

Felsenstein, J. (1985). Confidence limits on phylogenies: an approach using the bootstrap. Evolution 39, 783-791.

Felsenstein, J. (1993). PHYLIP (phylogeny inference package), version 3.5c. Distributed by the author. Department of Genome Sciences, University of Washington, Seattle, USA.

Fitch, W. M. \& Margoliash, E. (1967). Construction of phylogenetic trees: a method based on mutation distances as estimated from cytochrome $c$ sequences is of general applicability. Science 155, 279-284.

Goodfellow, M. \& Dawson, D. (1978). Qualitative and quantitative studies of bacteria colonizing Picea sitchensis litter. Soil Biol Biochem 10, 303-307.

Hasegawa, T., Takizawa, M. \& Tanida, S. (1983). A rapid analysis for chemical grouping of aerobic actinomycetes. J Gen Appl Microbiol 29, 319-322.

Huang, Y., Cui, Q., Wang, L., Rodriguez, C., Quintana, E., Goodfellow, M. \& Liu, Z. (2004). Streptacidiphilus jiangxiensis sp. nov., a novel actinomycete isolated from acidic rhizosphere soil in China. Antonie van Leeuwenhoek 86, 159-165. 
Kawato, M. \& Shinobu, R. (1959). On Streptomyces herbaricolor sp. nov., supplement: a simple technique for microscopical observation. Mem Osaka Unit Lib Arts Educ B Nat Sci 8, 114-119.

Khan, M. R. \& Williams, S. T. (1975). Studies on the ecology of actinomycetes in soil. VIII. Distribution and characteristics of acidophilic actinomycetes. Soil Biol Biochem 7, 345-348.

Kim, S. B., Falconer, C., Williams, E. \& Goodfellow, M. (1998). Streptomyces thermocarboxydovorans $\mathrm{sp}$. nov. and Streptomyces thermocarboxydus sp. nov., two moderately thermophilic carboxydotrophic species from soil. Int J Syst Bacteriol 48, 59-68.

Kim, S. B., Lonsdale, J. T., Seong, C. N. \& Goodfellow, M. (2003). Streptacidiphilus gen. nov., acidophilic actinomycetes with wall chemotype I and emendation of the family Streptomycetaceae (Waksman \& Henrici $1943^{\mathrm{AL}}$ ) emend. Rainey et al. 1997. Antonie van Leeuwenhoek 83, 107-116.

Kim, S. B., Seong, C. N., Jeon, S. J., Bae, K. S. \& Goodfellow, M. (2004). Taxonomic study on neutrotolerant acidophilic actinomycetes isolated from soil and description of Streptomyces yeochonensis sp. nov. Int J Syst Evol Microbiol 54, 211-214.

Kimura, M. (1980). A simple method for estimating evolutionary rates of base substitutions through comparative studies of nucleotide sequences. J Mol Evol 16, 111-120.

Kluge, A. G. \& Farris, F. G. (1969). Quantitative phyletics and the evolution of anurans. Syst Zool 18, 1-32.

Kroppenstedt, R. M. (1985). Fatty acid and menaquinone analysis of actinomycetes and related organisms. In Chemical Methods in Bacterial Systematics, pp. 173-199. Edited by M. Goodfellow \& D. E. Minnikin. London: Academic Press.

Lechevalier, H. A. \& Lechevalier, M. P. (1980). The chemotaxonomy of actinomycetes. In Actinomycete Taxonomy (Special Publication 6), pp. 277-284. Edited by A. Dietz \& D. W. Thayer. Arlington, VA: Society for Industrial Microbiology.

Lechevalier, M. P., De Bièvre, C. \& Lechevalier, H. A. (1977). Chemotaxonomy of aerobic actinomycetes: phospholipid composition. Biochem Syst Ecol 5, 249-260.

Liu, Z., Shi, Y., Zhang, Y., Zhou, Z., Lu, Z., Li, W., Huang, Y., Rodriguez, C. \& Goodfellow, M. (2005). Classification of Streptomyces griseus (Krainsky 1914) Waksman and Henrici 1948 and related species and the transfer of 'Microstreptospora cinerea' to the genus Streptomyces as Streptomyces yanii sp. nov. Int J Syst Evol Microbiol 55, 1605-1610.

Lonsdale, J. T. (1985). Aspects of the biology of acidophilic actinomycetes. PhD thesis, University of Newcastle, UK.

Manfio, G. P., Zakrzewska-Czerwinska, J., Atalan, E. \& Goodfellow, M. (1995). Towards minimal standards for the description of Streptomyces species. Biotekhnologia 7-8, 242-253.

Marmur, J. \& Doty, P. (1962). Determination of base composition of deoxyribonucleic acid from its denaturation temperature. J Mol Biol 5, 109-118.

Minnikin, D. E., O’Donnell, A. G., Goodfellow, M., Alderson, G., Athalye, M., Schaal, A. \& Parlett, J. H. (1984). An integrated procedure for the extraction of isoprenoid quinones and polar lipids. J Microbiol Methods 2, 233-241.

Saitou, N. \& Nei, M. (1987). The neighbor-joining method: a new method for reconstructing phylogenetic trees. Mol Biol Evol 4, 406-425.

Seong, C. N. (1992). Numerical taxonomy of acidophilic and neutrotolerant actinomycetes isolated from acid soil in Korea. PhD thesis, Seoul National University, Korea.

Seong, C. N., Goodfellow, M., Ward, A. C. \& Hah, Y. C. (1993). Numerical classification of acidophilic actinomycetes isolated from acid soil in Korea. Kor J Microbiol 31, 355-363.

Shirling, E. B. \& Gottlieb, D. (1966). Methods for characterization of Streptomyces species. Int J Syst Bacteriol 16, 313-340.

Thompson, J. D., Gibson, T. J., Plewniak, F., Jeanmougin, F. \& Higgins, D. G. (1997). The CLUSTAL_X windows interface: flexible strategies for multiple sequence alignment aided by quality analysis tools. Nucleic Acids Res 25, 4876-4882.

Van de Peer, Y. \& De Wachter, R. (1994). TREECON for windows: a software package for the construction and drawing of evolutionary trees for the Microsoft Windows environment. Comput Appl Biosci 10, 569-570.

Wang, L., Huang, Y., Cui, O., Xie, Q., Zhang, Y. \& Liu, Z. (2003). Isolation of acidophilic and acidoduric streptomycetes using dispersion and differential centrifugation approach. Microbiology [English translation of Microbiology (Beijing)] 30, 104-106.

Wayne, L. G., Brenner, D. J., Colwell, R. R. \& 9 other authors (1987). International Committee on Bacterial Systematics. Report of the ad hoc committee on reconciliation of approaches to bacterial systematics. Int J Syst Bacteriol 37, 463-464.

Williams, S. T. \& Flowers, T. H. (1978). The influence of $\mathrm{pH}$ on starch hydrolysis by neutrophilic and acidophilic actinomycetes. Microbios 20, 99-106.

Williams, S. T. \& Khan, M. R. (1974). Antibiotics - a soil microbiologist's viewpoint. Postepy Hig Med Dosw 28, 395-408.

Williams, S. T. \& Robinson, C. S. (1981). The role of streptomycetes in decomposition of chitin in acidic soils. J Gen Microbiol 127, 55-63.

Williams, S. T., Davies, F. L., Mayfield, C. I. \& Khan, M. R. (1971). Studies on the ecology of actinomycetes in soil. II. The $\mathrm{pH}$ requirements of streptomycetes from two acid soils. Soil Biol Biochem 3, 187-195.

Williams, S. T., Goodfellow, M., Alderson, G., Wellington, E. M. H., Sneath, P. H. A. \& Sackin, M. J. (1983). Numerical classification of Streptomyces and related genera. J Gen Microbiol 129, 1743-1813.

Williams, S. T., Goodfellow, M. \& Alderson, G. (1989). Genus Streptomyces Waksman and Henrici 1943, 339 AL. In Bergey's Manual of Systematic Bacteriology, vol. 4, pp. 2594-2598. Edited by S. T. Williams, M. E. Sharpe \& J. G. Holt. Baltimore: Williams \& Wilkins.

Wu, C., Lu, X., Qin, M., Wang, Y. \& Ruan, J. (1989). Analysis of menaquinone compound in microbial cells by HPLC. Microbiology [English translation of Microbiology (Beijing)] 16, 176-178. 